\title{
Psicooncología
}

ISSN: $1696-7240$

\section{Adaptación trascultural y validación del cuestionario PG-13 para la detección precoz de duelo prolongado}

Autora: Patricia Estevan Burdeus

Tipo de trabajo: Tesis doctoral

Directores: Elpidio Calvo Manuel y Cristina de Miguel Sánchez

Universidad: Universidad Complutense de Madrid, Facultad de Medicina, Departamento de Medicina.

Fecha de lectura: 03/02/2016

Entidades financiadoras: Fondos de Investigación en Salud del ISCIII (PI12/0952), Beca "Isabel Fernandez" de la SEMFyC para la realización de Tesis en la convocatoria 2012.

Agradecimientos: a Isabel del Cura, Teresa Sanz, Esperanza Escortell sin cuyo apoyo este trabajo no se habría hecho realidad. Y a David.

Email: Patricia.estevan@salud.madrid.org

\section{Resumen}

Objetivo: Realizar la adaptación trascultural y estudiar la validez y fiabilidad de la versión española del cuestionario PG-13. Determinar la prevalencia de duelo prolongado y los factores asociados.

Diseño: Fase 1. Adaptación trascultural de cuestionarios. Fase 2: Validación de pruebas diagnósticas.

Sujetos: Fase 1. Tres traductores ingles-castellano, tres traductores castellanoingles. Comité multidisciplinar: Tres psicólogos, médica y enfermera de cuidados paliativos, médica de Atención primaria.

Fase 2: Se ofreció participar a 330 personas mayores de edad que habían sufrido una pérdida hace más de 6 meses pero menos de 18 , elegidos por muestreo no probabilístico. Rechazaron 23, respuesta incompleta 7, participantes 299.

Metodología: Fase 1. Traducción-retrotraducción del cuestionario. Elaboración de versión inicial, estudio piloto y elaboración de la versión definitiva.

Fase 2. Estudio de fiabilidad test-retest $(n=26)$ repitiendo el cuestionario 7 días después de la primera entrevista y calculando el coeficiente kappa. Fiabilidad de la escala mediante el alfa de Cronbach. Validez lógica y de contenido mediante comité multidisciplinar. Validez de constructo: análisis factorial y asociación de DP con Trastorno de Ansiedad Generalizada (TAG), Episodio Depresivo Mayor (EDM), apoyo social percibido de Duke, presencia de DP medido con Inventario 
Texas Revisado de Duelo (ITRD) usando coeficiente phi de Pearson. Validez de criterio mediante comparación con entrevista clínica estandarizada $(n=84)$.

Resultados: Kappa=1. Alfa de Cronbach $=0,9183$. Validez de constructo: Correlación de DP con presencia de TAG, EDM, DP medido con ITRD y apoyo social percibido bajo. En el análisis factorial dos ítems explicaron el 62,4\% de varianza. Prevalencia DP: 7,04\%. Validez de criterio: Al comparar diagnóstico de DP mediante entrevista clínica con PG-13: Sensibilidad 50\%, Especificidad 94,29\%, Valor Predictivo Positivo 63,64\%, Valor Predictivo Negativo 90,41\%, Razón de Verosimilitud Positiva 8,75. El DP se asoció en análisis multivariante con presencia de EDM, haber precisado valoración por psiquiatra y tener unos ingresos familiares inferiores a 2000 euros al mes.

Conclusiones: El cuestionario PG-13 es una herramienta apta para el cribado de DP. 